\title{
Monitoramento temporal da pluma de contaminação no aterro de resíduos urbanos de Rio Claro (SP) por meio do método geofísico da eletrorresistividade
}

\author{
Temporal monitoring of the waste landfill contamination plume in Rio Claro (São Paulo, Brazil) \\ using geophysical resistivity method
}

\author{
José Ricardo Melges Bortolin ${ }^{1}$ e Walter Malagutti Filho² \\ ${ }^{1}$ Pós-graduação em Geociências e Meio Ambiente, Instituto de Geociências e Ciências Exatas, Universidade Estadual Paulista \\ "Júlio de Mesquita Filho" - UNESP, Avenida 24-A, 1.515, Caixa Postal 178, CEP 13506-900, Rio Claro, SP, BR (jrmb@bol.com.br) \\ ${ }^{2}$ Departamento de Geologia Aplicada, Instituto de Geociências e Ciências Exatas, Universidade Estadual Paulista "Júlio de \\ Mesquita Filho" - UNESP, Rio Claro, SP, BR (malaguti@rc.unesp.br)
}

Recebido em 22 de março de 2012; aceito em 10 de agosto de 2012

\begin{abstract}
Resumo
Diversos fatores têm contribuído para o aumento da produção mundial de resíduos sólidos urbanos, resultando em dificuldades no correto gerenciamento e disposição final ambientalmente adequada, além de ocasionar sérios problemas socioeconômicos, ambientais e de saúde pública. A contaminação de solos e águas subterrâneas por chorume nos locais de disposição dos resíduos quase sempre se faz presente, alavancando o surgimento e/ou a adaptação de metodologias para o diagnóstico ambiental destas áreas. Os métodos geofísicos, em especial o método da eletrorresistividade, são uma alternativa rápida, confiável e de baixo custo para esta finalidade. Neste artigo é reportada a metodologia adotada para o monitoramento temporal indireto da pluma de contaminação do aterro controlado do município de Rio Claro (SP). Dados de resistividade elétrica foram obtidos nos anos de 1999 e 2008, por meio do método da eletrorresistividade, empregando as técnicas da sondagem elétrica vertical e do imageamento elétrico. Em ambos os anos, foram executados ensaios semelhantes e nos mesmos locais, dentro da área do aterro. Os resultados indicaram que a pluma de contaminação apresenta valores de resistividade iguais ou menores a $50 \mathrm{ohm}$.m e se desloca segundo 2 sentidos de fluxo: o principal para sudeste e o secundário para oeste. Relativamente à primeira série de ensaios, em 1999, a pluma de contaminação apresentou-se maior e mais profunda no ano de 2008, contrariando o que se esperava para um aterro desativado há, pelo menos, 10 anos.
\end{abstract}

Palavras-chave: Resistividade elétrica; Aterro; Chorume; Sondagem elétrica vertical; Imageamento elétrico; Geofísica.

\begin{abstract}
Several factors have contributed to the increase the world production of urban solid waste, resulting in difficulties to the correct management and the final environmentally appropriate disposal, in addition to causing serious socio-economic, environmental, and public health troubles. The soil and groundwater contamination by leachate in waste disposal sites is almost always present, leveraging the emergence and/or adaptation of methodologies for environmental assessment of these areas. The geophysical methods, especially the electrical resistivity method, are fast, reliable and low-cost alternative for this purpose. This paper reports the methodology adopted for the temporal monitoring of the plume of contamination of controlled landfill in the municipality of Rio Claro (SP). Electrical resistivity data were obtained in 1999 and 2008 , by the resistivity method, using the techniques of vertical electrical sounding and electrical profile. In both years, similar tests were carried out in the same locations within the disposal area. The results indicated that the plume of contamination has resistivity values less than or equal to $50 \mathrm{ohm} . \mathrm{m}$ and moves guided by 2 flows: the main, to the southeast, and the secondary, to the west. Relatively to the first series of tests in 1999, the plume of contamination was higher and deeper in 2008, contrary to what was expected for a landfill deactivated for at least 10 years.
\end{abstract}

Keywords: Electrical resistivity; Landfill; Leachate; Vertical electrical sounding; Electrical profile; Geophysics. 


\section{INTRODUÇÃO}

Nas últimas décadas, fatores como o acelerado crescimento populacional, a urbanização desenfreada, o aumento no poder aquisitivo e os novos hábitos de consumo de grande parte da população têm contribuído significativamente para o incremento da produção mundial de resíduos sólidos urbanos.

Devido às políticas de ordenamento territorial e gestão ambiental inexistentes e/ou ineficientes, locais técnica e geologicamente inapropriados são utilizados para a disposição final dos resíduos sólidos gerados nos centros urbanos, resultando em danos, muitas vezes irreversíveis, ao meio natural.

Ao menos desde a década de 1980, vários projetos de lei, decretos e resoluções tramitaram (e ainda tramitam) as mais diversas esferas políticas, na tentativa de se regulamentar a produção, o transporte e a correta destinação final dos resíduos sólidos urbanos. Entretanto, os primeiros resultados positivos destes esforços surgiram somente no final da década de 1990 e os principais resultados até então, após a virada do novo milênio: Lei Federal $\mathrm{n}^{\circ}$ 12.305, de 2 de agosto de 2010 (Política Nacional de Resíduos Sólidos); Lei Estadual no 12.300, de 16 de março de 2006 (Política Estadual de Resíduos Sólidos) (São Paulo, 2006) e Resolução CONAMA n ${ }^{\circ} 404$, de 11 de novembro de 2008 (Brasil, 2008), que estabelece critérios e diretrizes para o licenciamento ambiental de aterro sanitário de pequeno porte de resíduos sólidos urbanos.

\section{Áreas de disposição de resíduos sólidos no Brasil}

No Brasil, existem, basicamente, três diferentes tipos de locais para a disposição final de resíduos sólidos urbanos, classificados de acordo com a estrutura do local e com a forma de disposição dos resíduos:

- Lixão: local utilizado para disposição do lixo, em bruto, sobre o terreno sem qualquer cuidado ou técnica especial, e caracterizado pela falta de medidas de proteção ao meio ambiente ou à saúde pública (Brasil, 2002);

- Aterro controlado: aterro para lixo residencial urbano, onde os resíduos são depositados recebendo depois uma camada de terra por cima (São Paulo, 2008);

- Aterro sanitário: aterro para lixo residencial urbano com pré-requisitos de ordem sanitária e ambiental, como impermeabilização do solo, para evitar infiltração de chorume até os lençóis freáticos e consequente contaminação das águas; sistema de drenagem de chorume, para ser tratado em local adjunto específico; sistema de drenagem de gases, para evitar o risco de explosões e deslizamentos (São Paulo, 2008).

Segundo o IBGE (Brasil, 2002), a opção por lixões e aterros é a mais comum em terras brasileiras e representa cerca de $99 \%$ da destinação final do total de resíduos coletados, sendo que $47,1 \%$ dos resíduos coletados são dispostos em aterros sanitários, $22,3 \%$ em aterros controlados e $30,5 \%$ em lixões. Sendo assim, é bastante comum encontrar lixões e aterros controlados que apresentem algum grau de contaminação de solos e águas subterrâneas por chorume.

\section{Contaminação ambiental e investigação geofísica}

Inicialmente, chorume era o nome atribuído a uma substância gordurosa expelida pelo tecido adiposo de animais. Posteriormente, o significado da palavra foi ampliado e passou a significar o líquido contaminante, de cor escura, odor nauseante e de elevada demanda bioquímica de oxigênio (DBO), originado de processos biológicos, químicos e físicos da decomposição de resíduos orgânicos (Bortolin, 2009).

Diferentemente ao que ocorre com as águas superficiais, o combate à contaminação das águas subterrâneas é complexo, oneroso, exige muito tempo e, em muitos casos, torna-se impraticável. Por isso, órgãos públicos e instituições de pesquisa têm voltado sua atenção a esses casos, no sentido de diagnosticar e avaliar os impactos ambientais gerados (Moura e Malagutti Filho, 2003).

Diante desse cenário, surgem os métodos geofísicos de investigação como uma eficiente e importante ferramenta para o estudo do meio natural, com a vantagem da versatilidade de aplicações, precisão dos resultados e rapidez na avaliação de grandes áreas com custo relativamente menor, frente aos tradicionais métodos de investigação, como as sondagens e os poços de monitoramento.

Ao longo dos anos, os métodos geofísicos têm-se mostrado eficientes na avaliação e caracterização de problemas ambientais, e amplamente utilizados na investigação e monitoramento de poluição subterrânea; além disso, são de natureza não invasiva, o que significa que, a priori, não alteram o meio físico (Bortolin, 2009).

Em meio aos diversos métodos geofísicos passíveis de serem empregados, destacam-se aqueles que medem os parâmetros físicos e/ou químicos da água subterrânea, que sofrem influência direta pela presença de contaminantes. O método da eletrorresistividade (ER), em especial, é largamente utilizado na prospecção de águas subterrâneas e possui sensibilidade suficiente para detectar a presença de alguns tipos de contaminantes.

O chorume é um contaminante extremamente agressivo e pode atacar os metais contidos nos resíduos, liberando íons que se agregam aos materiais geológicos. Locais contaminados por chorume, como lixões e aterros, contêm eletrólitos ricos em íons, favorecendo, assim, a condução de corrente elétrica na forma iônica.

Assim, contaminações por chorume em subsuperfície podem ser detectadas pelo método da ER, pois nesses locais os valores de resistividade são mais baixos. 


\section{Breve revisão de literatura}

Inúmeros trabalhos podem ser encontrados na literatura científica, relatando a utilização do método da ER, aplicado com as técnicas do imageamento elétrico (IE) e da sondagem elétrica vertical (SEV), em estudos de contaminação ambiental em áreas de disposição de resíduos: na pré-operação do Aterro Metropolitano Centro, na cidade de Salvador (BA) (Cavalcanti, Sato, Lima, 2001), nos lixões de Cuiabá (MT) (Shiraiwa et al., 2002) e Ribeirão Preto (SP) (Silva et al., 2002), nos aterros controlados de Rio Claro (SP) (Moura e Malagutti Filho, 2003) e Piracicaba (SP) (Moura e Malagutti Filho, 2007), e no aterro sanitário de Bauru (SP) (Lago, Elis, Giacheti, 2006).

Entretanto, Bortolin (2009) afirma que, para que seja possível compreender plenamente o comportamento do contaminante e planejar de modo eficiente a remediação do problema, é desejável que se faça um acompanhamento da situação, monitorando temporalmente a área. Isto é feito, basicamente, por meio da repetição de ensaios idênticos em locais pré-definidos e pela comparação dos resultados obtidos.

Porém, são escassas as obras que abordam este tema. São exemplos dessa metodologia os trabalhos desenvolvidos em uma área do distrito industrial no município de Araras (SP) (Moreira e Dourado, 2007; Moreira, Aquino, Dourado, 2007; Moreira e Braga, 2009) e, mais especificamente, os trabalhos desenvolvidos por Moreira (2009) no aterro controlado de Cordeirópolis (SP), onde foram aplicados os métodos de ER, IP e SP.

Neste último, os dados foram obtidos sobre 13 valas fechadas sempre ao mês de dezembro, entre os anos de 2001 e 2007, e os resultados indicam que os valores dos parâmetros investigados estão diretamente relacionados ao tempo de permanência dos resíduos nas valas.

Os maiores valores de cargabilidade (método IP) foram detectados em valas recém-fechadas (2007), diminuindo gradativamente em direção às valas mais antigas (2001) e no método do SP, os maiores valores (positivos) estão associados às valas mais antigas, enquanto que na vala referente ao ano de 2007, os valores são próximos a zero.

Os valores de resistividade elétrica também variaram conforme o tempo de fechamento das valas: aquelas fechadas no início da operação do aterro (2001) apresentam valores relativamente maiores aos verificados em valas fechadas mais recentemente, atingindo o limiar de $500 \Omega$.m em 2001 e $100 \Omega . m$ em 2007.

\section{Objetivo}

Perante o exposto, objetivou-se monitorar temporalmente a pluma de contaminação sob o aterro controlado de Rio Claro (SP), entre os anos de 1999 e 2008, utilizando-se uma metodologia baseada no método da ER, cujos resultados obtidos são apresentados neste trabalho.

\section{Localização e descrição da área de estudos}

$\mathrm{O}$ aterro controlado de Rio Claro (SP) (Figura 1) localiza-se ao sul do município, às margens da Rodovia Fausto Santomauro (SP 127), a qual interliga os municípios de Rio Claro e Piracicaba, na altura do $\mathrm{km} 3$ da faixa de sentido Rio Claro-Piracicaba, e possui uma área de 44.242,16 $\mathrm{m}^{2}$ (Tandel, 1998).

Esse local teve origem no ano de 1982, como um lixão instalado numa antiga voçoroca, e foi concebido para receber resíduos de origem dos serviços de limpeza pública do município. Entre 1988 e 1992, o gerenciamento do local ficou a cargo da empresa Sistemas de Proteção Ambiental Ltda. (SPA), a qual realizou a instalação de drenos para a coleta de gases e de percolado, transformando o antigo lixão em aterro controlado.

Os drenos foram construídos com brita de basalto $\mathrm{n}^{\circ} 4$. O percolado era conduzido por canaletas de concreto até um poço concretado do sistema de recirculação, sendo que a quantidade gerada era de, no máximo, 42 litros por hora na época das chuvas, chegando a zero na seca. Os gases eram eliminados nos queimadores, mantidos constantemente acesos. A base do aterro não recebeu nenhum tipo de impermeabilização. Segundo Tandel (1998), ensaios de laboratório apontam valores do coeficiente de permeabilidade da base do aterro nunca superiores a $10^{-6} \mathrm{~cm} / \mathrm{s}$.

Os resíduos coletados eram dispostos diretamente no aterro, sem separação ou tratamento intermediário, em células de $4 \mathrm{~m}$ de altura, em média. Eram recobertos com uma camada de material de cobertura com cerca de 0,5 $\mathrm{m}$ e compactado por trator de esteira. A densidade final de compactação girava em torno de $600 \mathrm{~kg} / \mathrm{m}^{3}$ (Braz e Silva, 2001).

As atividades no aterro foram encerradas em setembro de 1997 e, em caráter emergencial, utilizou-se uma área contígua, a leste do aterro. Após o término das operações de disposição de resíduos, todo o aterro foi coberto com uma camada de solo de, aproximadamente, $0,5 \mathrm{~m}$. No entorno do aterro verifica-se o domínio de lavouras de cana-de-açúcar, destinadas a atender a agroindústria do açúcar e do álcool.

\section{Contexto geológico}

Em termos geológicos, a cidade de Rio Claro (SP) está situada no setor paulista do flanco nordeste da Bacia Sedimentar do Paraná, representada por rochas sedimentares e vulcânicas das eras Paleozoica, Mesozoica e Cenozoica. Segundo Cottas (1983) e Zaine (1994), as unidades litoestratigráficas que afloram na região do aterro são: 
- Formação Corumbataí: constituída por argilitos, siltitos e folhelhos, com intercalações de arenitos de granulometria fina, leitos carbonáticos e coquinas até o topo da formação. Sua espessura na região de Rio Claro (SP) não ultrapassa os $130 \mathrm{~m}$;

- Formação Rio Claro: assentada discordantemente sobre rochas da Formação Corumbataí. Apresenta fraca litificação e profunda alteração pedogenética, espesso solo arenoso ( 8 a $12 \mathrm{~m}$ ) e arenitos, variando de areia fina a grossa, intercaladas com camadas de conglomerados e de sedimentos argilosos. Possui espessura média entre 25 e 30 m e máxima da ordem de 40 m (dados obtidos na perfuração de poços no Distrito Industrial do município).

A base do aterro encontra-se na Formação Rio Claro e a cava de resíduos apresenta forma de vale.

\section{MÉTODOS}

No ano de 1999, Moura (2002) executou uma série de ensaios geofísicos na referida área empregando o método da ER. Em 2008, novos ensaios foram executados por Bortolin (2009) de forma análoga e nos mesmos locais determinados anteriormente, e os resultados obtidos nos diferentes anos foram comparados entre si, de modo que se determinou a evolução temporal da pluma de contaminação sob o aterro.

\section{Embasamento teórico}

O método da ER é calcado no fato de que diferentes materiais, geológicos ou não, apresentam diferentes valores de resistividade elétrica $(\rho)$; esta é uma das propriedades fundamentais dos diferentes materiais geológicos e está

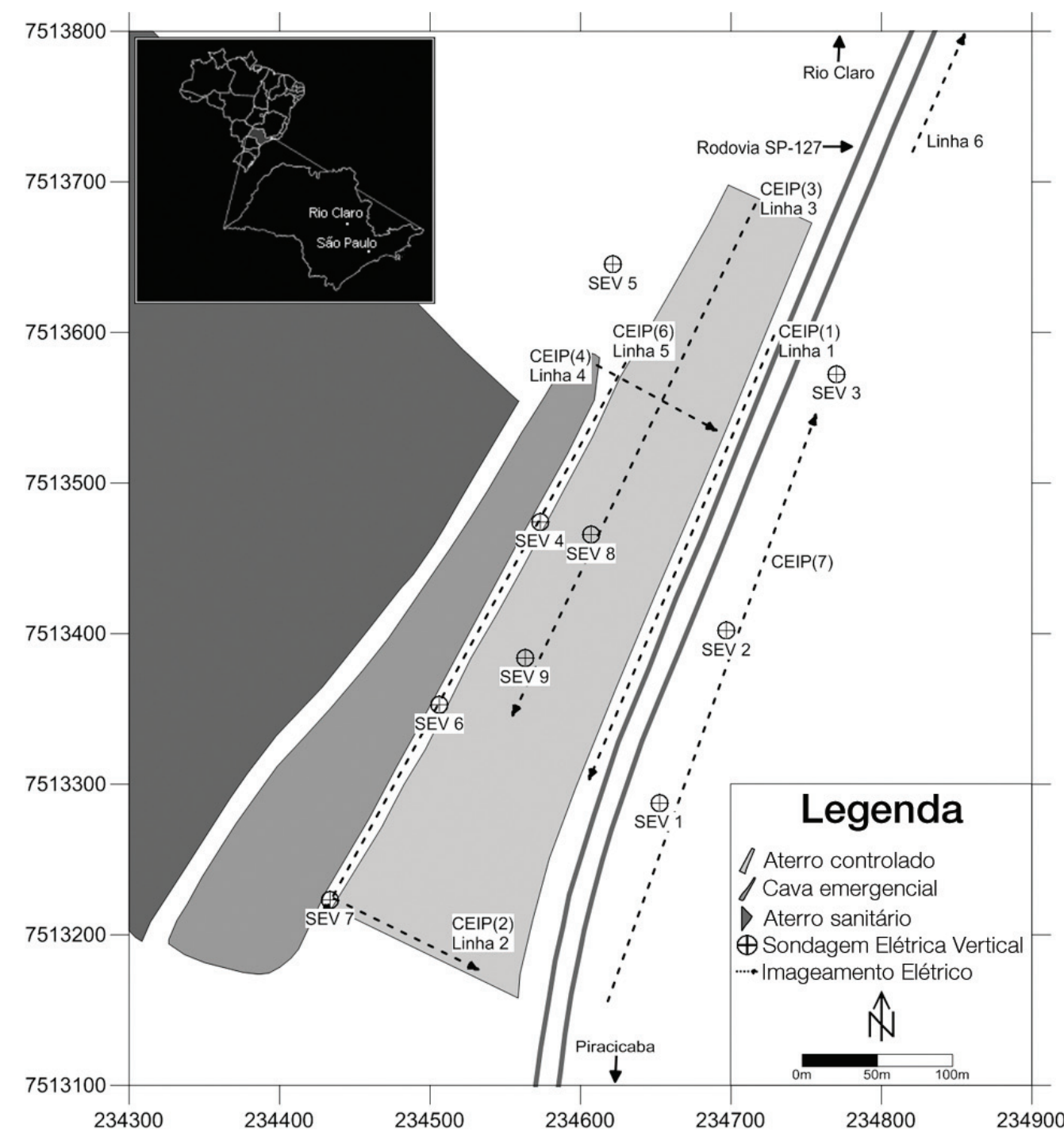

Figura 1. Localização da área de estudos, indicando a posição dos ensaios geofísicos. 
relacionada à facilidade encontrada por uma corrente elétrica para se propagar em um meio.

Em linhas gerais, a resistividade elétrica em um meio geológico pode ser calculada através da Equação (1):

$\rho=\frac{\Delta V}{I} K$

Onde a unidade de medida de $\rho$ é o ohm.m, I é a corrente elétrica injetada no solo (dada em ampères) através dos eletrodos de corrente $\mathrm{A}$ e $\mathrm{B}, \Delta V$ representa o potencial medido (em Volts) entre os eletrodos $\mathrm{M}$ e N, e $K$ é chamado de fator geométrico e depende da distância entre os eletrodos.

A Equação 1 é válida unicamente para a situação ideal de um meio geológico homogêneo e isotrópico. Entretanto, uma sucessão de camadas com diferentes valores de resistividade constituem os meios geológicos reais, tornando-os heterogêneos e anisotrópicos; portanto, na prática, a situação ideal dificilmente se verifica.

Assim, se efetuarmos as medidas de resistividade elétrica em um meio geológico comum e levarmos os dados obtidos à Equação 1, resultará uma resistividade fictícia $\rho_{\mathrm{a}}$, a qual dependerá da resistividade de cada camada geológica e das distâncias entre os eletrodos. Esta resistividade fictícia $\left(\rho_{\mathrm{a}}\right)$ é chamada de resistividade aparente, a qual é uma variável experimental que expressa os resultados obtidos nas medições do método da ER e que se toma como base para a interpretação (Orellana, 1972). Sua unidade de medida também é o ohm.m ( $\Omega . m)$.

No decorrer dos anos, diversas técnicas foram desenvolvidas para a aplicação do método da eletrorresistividade. As principais - e que foram utilizadas no presente trabalho são a SEV e o IE ou caminhamento elétrico (CE) e elas diferem entre si em função do tipo de investigação pretendida.

\section{Sondagem elétrica vertical}

Consiste na investigação da variação de um parâmetro físico - no caso, a resistividade elétrica - em diversas profundidades, a partir de medidas efetuadas na superfície do terreno. $\mathrm{O}$ arranjo utilizado foi o Schlumberger, conforme ilustra a Figura 2.

Neste arranjo, a distância entre os eletrodos de corrente A e $\mathrm{B}$ deve ser, no mínimo, cinco vezes maior, ou igual, à distância entre os eletrodos de potencial $\mathrm{M}$ e $\mathrm{N}$ conforme a Equação 2:

$$
\mathrm{MN} \leq \frac{A B}{5}
$$

O coeficiente geométrico $K_{\mathrm{s}}$, para o arranjo Schlumberger, é dado pela Equação 3:

$\mathrm{K}_{\mathrm{s}}=\pi \frac{(A M \cdot A N)}{M N}$

Onde $A M, A N$ e $M N$ representam, respectivamente, as distâncias entre os eletrodos A e M, A e N, e M e N.

A aquisição dos dados foi feita utilizando-se um resistivímetro BISON 2390. O máximo espaçamento $A B / 2 \mathrm{em}-$ pregado foi de $100 \mathrm{~m}$ nas SEV dentro do aterro e de 150 $\mathrm{m}$ nas SEV fora do aterro, totalizando 9 ensaios. Os dados foram processados no software Interpex IX1D, versão 2.17 (Interpex Limited, 2008).

As SEV foram distribuídas de modo a se estabelecer uma malha otimizada, de espaçamento aproximadamente regular, sem a preocupação demasiada de coincidi-las com os ensaios anteriores, executados por Moura (2002), pois serviram de base para a interpretação dos resultados dos IE e para a elaboração do mapa potenciométrico da área.

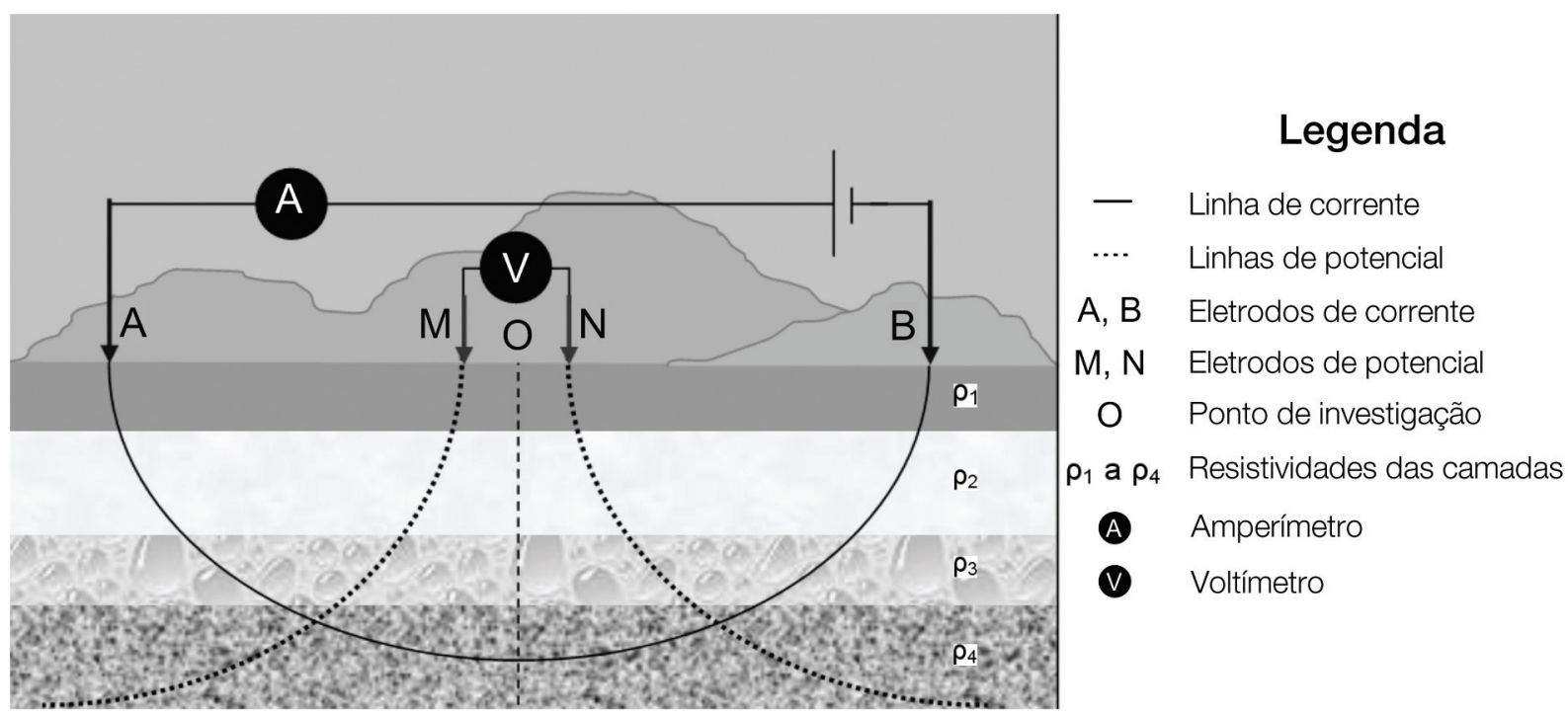

Figura 2. Técnica da sondagem elétrica vertical com arranjo Schlumberger (Bortolin, 2009). 


\section{Imageamento elétrico}

Trata-se da obtenção de valores de um parâmetro físico novamente, a resistividade elétrica - , a partir da superfície terrestre, ao longo de uma seção, e na interpretação da sua variação horizontal a uma ou mais profundidades determinadas. $\mathrm{O}$ arranjo utilizado foi o dipolo-dipolo com cinco níveis de investigação (Figura 3).

Nesse arranjo, os eletrodos de corrente A e B e os eletrodos de potencial $\mathrm{M}$ e $\mathrm{N}$ são dispostos sobre uma mesma linha reta imaginária e o espaçamento entre os eletrodos $(x)$ obedece à relação $x=A B=M N$.

A profundidade teórica de investigação $(Z)$ aumenta conforme a distância de separação dos dipolos $(R)$ e é dada por $Z=R / 2$.

Os pontos de investigação são determinados traçando-se segmentos de reta, partindo do centro geométrico de $A B$ e $M N$, com inclinação de $45^{\circ}$ em relação à superfície, de modo que se encontrem em certa profundidade.

O fator geométrico $K_{\mathrm{DD}}$ para o arranjo dipolo-dipolo é dado pela Equação 4:

$$
\mathrm{K}_{\mathrm{DD}}=2 \pi x \frac{1}{\left(\frac{1}{n}-\frac{2}{n+1}+\frac{1}{n+2}\right)}
$$

Onde o coeficiente $n$ representa o nível de investigação e pode assumir somente valores inteiros e positivos, isto é, $n=1,2,3, \ldots$

Foram executadas 6 linhas de IE, com extensões que variaram entre $90 \mathrm{~m}$ e $420 \mathrm{~m}$. A aquisição dos dados no ano de 1999 foi feita utilizando-se um transmissor SCINTREX TSQ-3 e um receptor SCINTREX IPR-12 e, em 2008, com um resistivímetro ABEM TERRAMETER SAS 4000 e um resistivímetro BISON 2390.

Os dados dos IE executados em 1999 e em 2008 foram processados com o software Res2dinv v.3.4 (Geotomo
Software, 2002), utilizando o mesmo tipo de processamento para todas as seções, as quais foram comparadas qualitativa e quantitativamente entre si, possibilitando traçar uma linha evolutiva da pluma de contaminação presente na área.

\section{RESULTADOS E DISCUSSÃO}

\section{Sondagens elétricas verticais}

Com a finalidade de subsidiar a interpretação dos resultados dos IE, foram executadas $9 \mathrm{SEV}$, sendo 7 externas e 2 internas ao aterro (Figura 1). A Figura 4 exibe as curvas de campo referentes a cada uma das SEV executadas.

De modo a facilitar a interpretação dos dados de SEV, as respectivas curvas foram agrupadas segundo o local de realização de cada ensaio. Assim, estes ensaios foram divididos em dois grupos principais:

- Grupo 1: ensaios realizados fora da área do aterro (SEV 01 a SEV 07)
a) Subgrupo 1-A: SEV 01 a 03
b) Subgrupo 1-B: SEV 04 a 07

- Grupo 2: ensaios realizados dentro da área do aterro (SEV 08 e SEV 09)

Para melhor entendimento dos resultados obtidos por meios das SEV, foram elaboradas três tabelas que apresentam, de forma sucinta, o arcabouço geoelétrico interpretado da área de estudos (Tabelas 1 a 3).

Mediante a interpretação das curvas das SEV, assumiu-se que a base do aterro encontra-se na Formação Rio Claro, assim como levantado em trabalhos anteriores (Tandel, 1998; Moura, 2002). Esta interpretação foi feita norteada pelos valores de resistividade elétrica obtidos

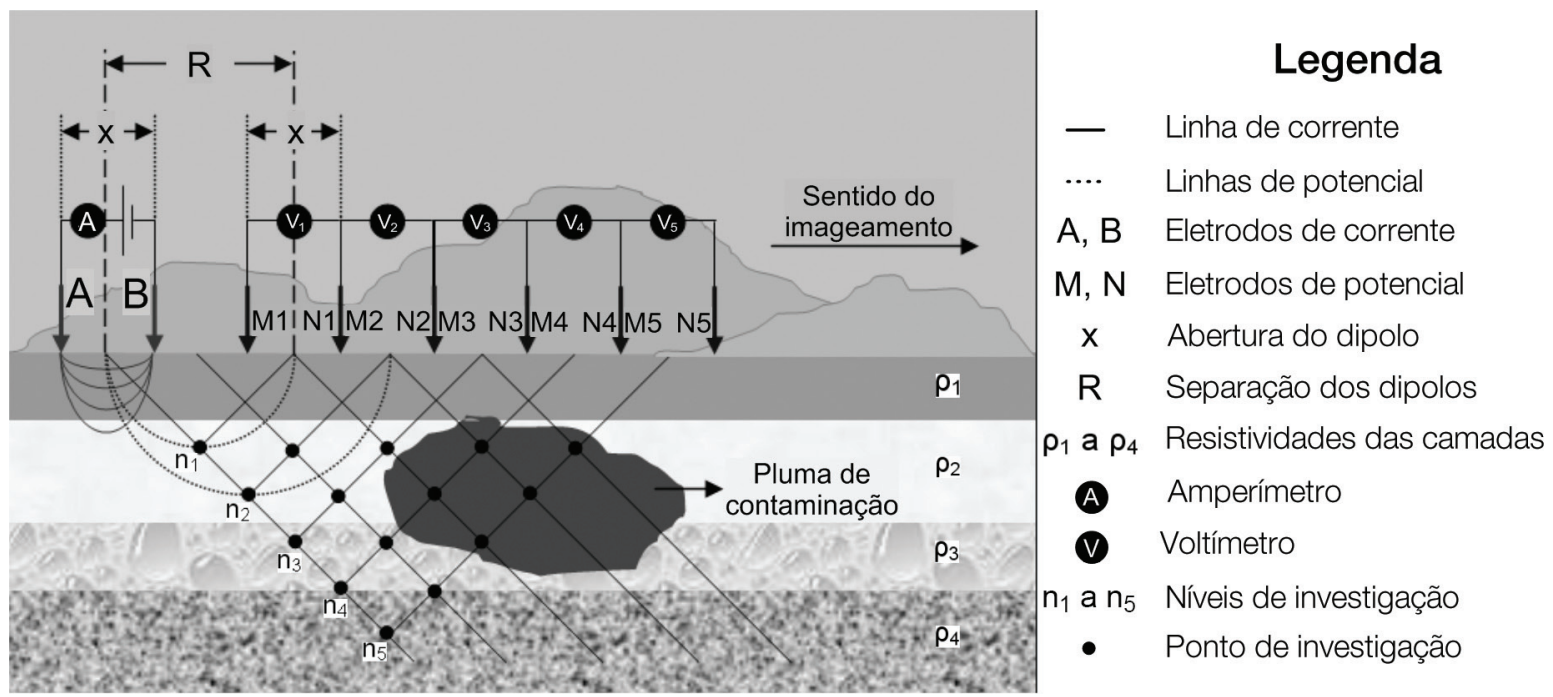

Figura 3. Técnica do imageamento elétrico com arranjo dipolo-dipolo (Bortolin, 2009). 
— entre $1.760 \Omega . \mathrm{m}$ a $3.250 \Omega . \mathrm{m}$ - típicos de sedimentos arenosos insaturados do contexto geológico da área (Braga, 1997).

Por meio das SEV 01, 02 e 03 (exteriores ao aterro) foi possível detectar uma camada de sedimentos argilosos, intercalada aos sedimentos arenosos da Formação Rio Claro, ocorrendo entre as cotas $560 \mathrm{~m}$ e $578 \mathrm{~m}$. Existe a possibilidade de que essa camada argilosa apresente continuidade lateral, estendendo-se em direção à cava de resíduos, e atue como impermeabilizante natural da base do aterro, que se encontra, aproximadamente, entre as cotas $566 \mathrm{~m}$ e $574 \mathrm{~m}$. Esta hipótese sustenta, inclusive, a ocorrência de sedimentos arenosos secos na base do aterro.

Porém, na interpretação das curvas das SEV 08 e 09 (executadas sobre a cava de resíduos), não foi possível distinguir geoeletricamente a camada argilosa dos resíduos, já que ambos os materiais podem apresentar resistividade elétrica $\leq 20 \Omega$.m.

Ainda por meio da interpretação das curvas das SEV, foi possível gerar o mapa potenciométrico da área de estudos (Figura 5) e identificar que o nível freático, no período da estiagem, está situado entre $9,10 \mathrm{~m}$ e 14,80 m e tem sentido de fluxo para Sudeste (SE).

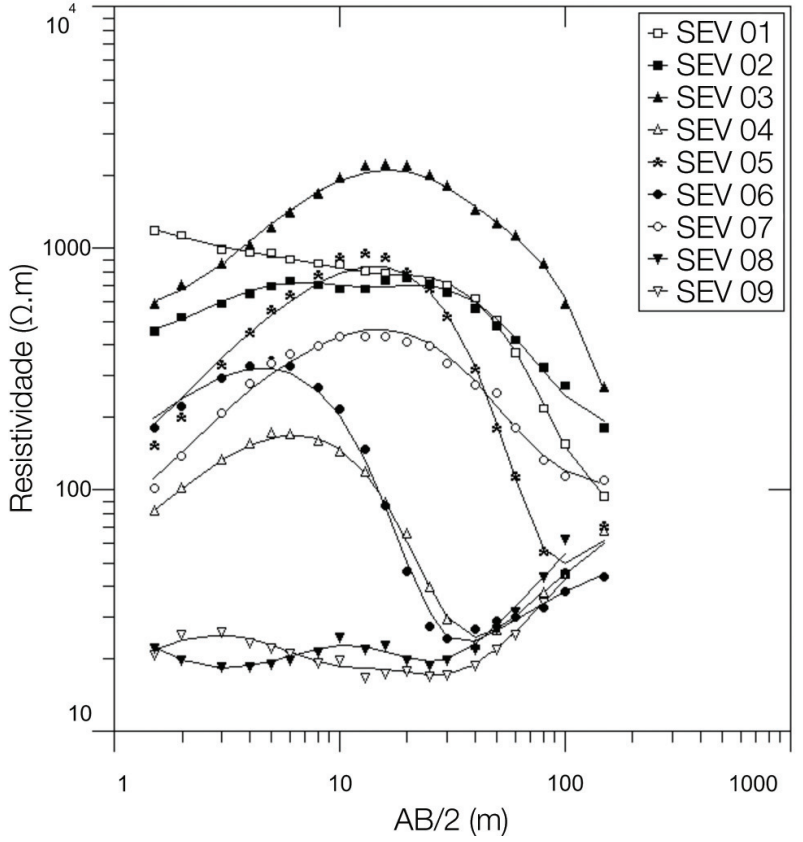

Figura 4. Curvas de campo das nove sondagens elétricas verticais agrupadas (Bortolin, 2009).

Tabela 1. Modelo geoelétrico proposto para o subsolo do Subgrupo 1-A (SEV 01 a 03).

\begin{tabular}{lccc}
\hline $\begin{array}{l}\text { Nível } \\
\text { geoelétrico }\end{array}$ & Interpretação & Resistividade $(\Omega . m)$ & $\begin{array}{c}\text { Espessura } \\
(\mathrm{m})\end{array}$ \\
\hline 1 & Solo residual arenoso e seco & $403 \leq \rho_{1} \leq 1.410$ & $0,70 \leq \mathrm{E}_{1} \leq 1,80$ \\
\hline 2 & Sedimentos predominantemente arenosos secos & $\begin{array}{c}925 \leq \rho_{2} \leq 1.594 \\
10.400^{*}\end{array}$ & $1,80 \leq \mathrm{E}_{2} \leq 5,60$ \\
\hline 3 & Sedimentos predominantemente arenosos com provável & $108 \leq \rho_{3} \leq 197$ & $1,70 \leq \mathrm{E}_{3} \leq 1,90$ \\
\hline 4 & intercalação de argilito & $1.424 \leq \rho_{4} \leq 5.446$ & $4,50 \leq \mathrm{E}_{4} \leq 10,00$ \\
\hline 5 & Sedimentos predominantemente arenosos secos & $211 \leq \rho_{5} \leq 270$ & $4,00 \leq \mathrm{E}_{5} \leq 9,20$ \\
\hline 6 & Sedimentos predominantemente silto-argilosos & 36 & - \\
\hline
\end{tabular}

*com prováveis estruturas conglomeráticas

** possivelmente fraturados

Tabela 2. Modelo geoelétrico proposto para o subsolo do Subgrupo 1-B (SEV 04 a 07).

\begin{tabular}{|c|c|c|c|}
\hline $\begin{array}{l}\text { Nível } \\
\text { geoelétrico }\end{array}$ & Interpretação & Resistividade ( $\Omega . \mathrm{m})$ & $\begin{array}{l}\text { Espessura } \\
\text { (m) }\end{array}$ \\
\hline 1 & Solo residual arenoso com influência dos resíduos & $22 \leq \rho_{1} \leq 65$ & $0,30 \leq E_{1} \leq 0,40$ \\
\hline 2 & Sedimentos predominantemente arenosos & $\begin{array}{c}783 \leq \rho_{2} \leq 3.719 \\
11.555^{\star}\end{array}$ & $1,00 \leq E_{2} \leq 1,80$ \\
\hline 3 & $\begin{array}{l}\text { Sedimentos predominantemente arenosos com possível } \\
\text { influência dos resíduos }\end{array}$ & $140 \leq \rho_{3} \leq 437$ & $1,70 \leq \mathrm{E}_{3} \leq 7,90$ \\
\hline 4 & Sedimentos predominantemente arenosos com chorume & $24 \leq \rho_{4} \leq 28$ & $5,80 \leq \mathrm{E}_{4} \leq 9,30$ \\
\hline 5 & $\begin{array}{l}\text { Sedimentos predominantemente arenosos saturados com } \\
\text { chorume (N.A.) }\end{array}$ & $\begin{array}{c}2 \leq \rho_{5} \leq 12 \\
178^{\star \star}\end{array}$ & $2,10 \leq E_{5} \leq 12,70$ \\
\hline 6 & Sedimentos predominantemente silto-argilosos a silto-arenosos ${ }^{+}$ & $62^{\#} \leq \rho_{6} \leq 192^{\#+}$ & - \\
\hline
\end{tabular}

* com prováveis estruturas conglomeráticas

** não contaminados ou com baixo nível de contaminação

\# possivelmente fraturados 


\section{Imageamentos elétricos (monitoramento temporal)}

\section{Monitoramento temporal: $\operatorname{CEIP(7)~e~Linha~} 6$}

Conhecer o comportamento de um local isento de contaminação adjacente à área de estudos é imprescindível para

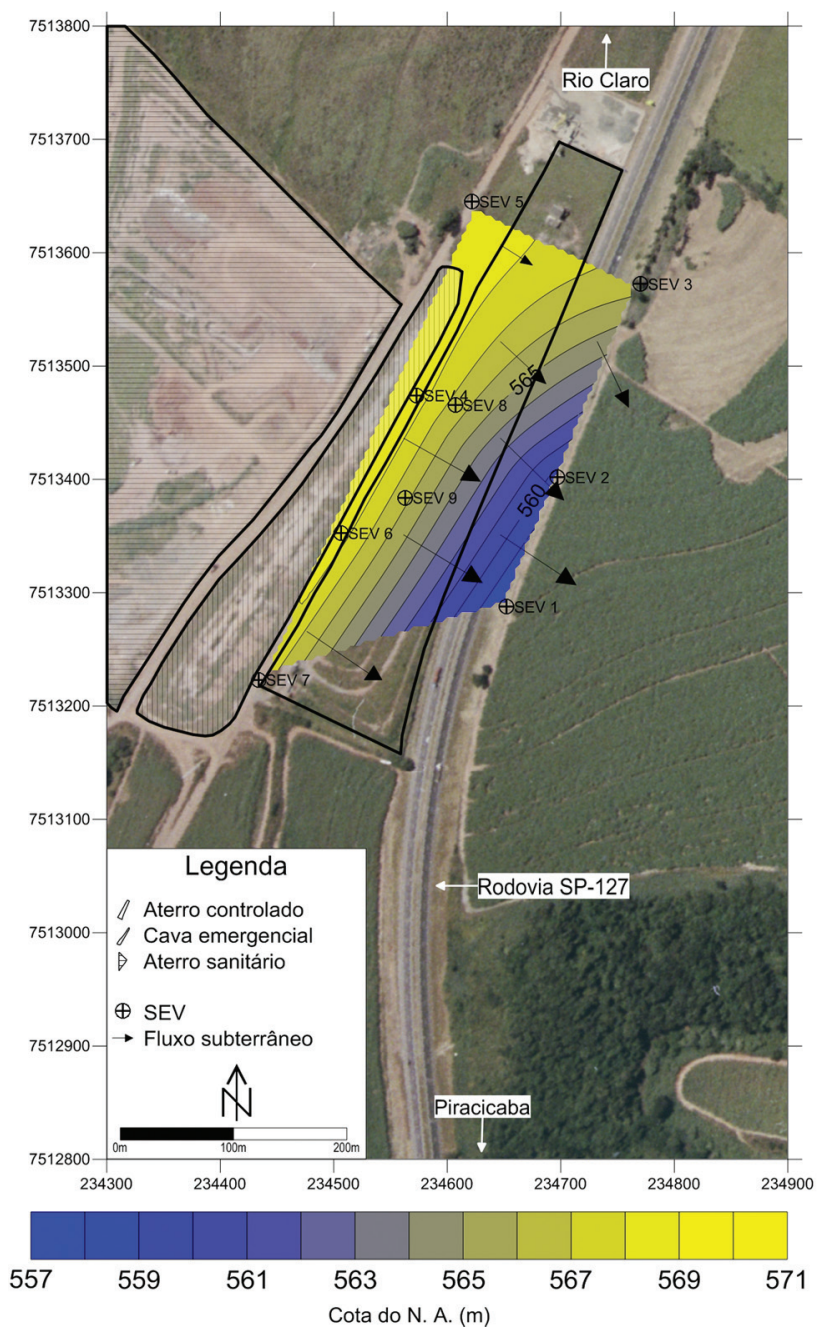

Figura 5. Mapa potenciométrico da área de estudos, indicando o sentido do fluxo para sudeste (Bortolin, 2009). que seja possível identificar anomalias geofísicas que indiquem a existência de algum contaminante no subsolo. Para esta finalidade, devem ser realizados ensaios de referência e que, neste caso, indicaram os valores de background de resistividade elétrica da área.

Assim, por meio dos ensaios CEIP(7) e Linha 6, adotados como referências em 1999 e 2008, respectivamente, e cujas seções de resistividade são apresentadas na Figura 6, foi possível delimitar o background da área, onde valores iguais ou maiores a $140 \Omega$.m indicam ambiente natural isento de contaminação por chorume. Desse modo, definiu-se que valores abaixo de $140 \Omega$.m indicam provável contaminação por chorume.

É conveniente ressaltar que a Linha 6 foi localizada a cerca de $150 \mathrm{~m}$ de distância a montante da área de estudos (Figura 1), diferentemente do ensaio $\operatorname{CEIP(7),~reali-~}$ zado em local que intercepta o fluxo d'água subterrâneo proveniente do aterro. A opção pelo local de execução da Linha 6 foi para garantir que não houvesse nenhuma influência dos resíduos sobre os resultados obtidos. Apesar disso, como se pode notar na Figura 6, ambas as seções apresentam o mesmo valor mínimo de resistividade, sugerindo que não houve alteração (ao menos, não significativa) dos valores de referência de resistividade no intervalo de tempo decorrido entre a realização dos dois ensaios geofísicos, independentemente do local de realização e da extensão de cada um.

\section{Monitoramento temporal: $\operatorname{CEIP(1)~e~Linha~} 1$}

As zonas de baixa resistividade ( $\leq 50 \Omega . \mathrm{m})$ encontradas principalmente em profundidades superiores a $12 \mathrm{~m}$ na seção do ensaio CEIP(1) (Figura 7), foram interpretadas por Moura (2002) como sedimentos arenosos da Formação Rio Claro contaminados pelo percolado. Também na seção da Linha 1 verificam-se zonas de baixa resistividade, porém mais rasas (cerca de $5 \mathrm{~m}$ de profundidade) e concentradas a partir da estaca de $180 \mathrm{~m}$ (Figura 7).

As diferenças verificadas na localização das zonas de baixa resistividade podem sugerir o transporte do percolado pelo lençol freático para a direção $\mathrm{SO}$, já que o fluxo

Tabela 3. Modelo geoelétrico proposto para o subsolo do Grupo 2 (SEV 8 e 9).

\begin{tabular}{|c|c|c|c|}
\hline $\begin{array}{l}\text { Nível } \\
\text { geoelétrico }\end{array}$ & Interpretação & $\begin{array}{c}\text { Resistividade } \\
(\Omega . \mathrm{m})\end{array}$ & $\begin{array}{c}\text { Espessura } \\
(\mathrm{m})\end{array}$ \\
\hline 1 & Material de cobertura do aterro (úmido?) com influência dos resíduos & $12 \leq \rho_{1} \leq 38$ & $0,50 \leq E_{1} \leq 0,60$ \\
\hline 2 & Resíduos & $\rho_{2}=16$ & $E_{2}=3,30$ \\
\hline 3 & Material de cobertura do aterro com chorume & $78 \leq \rho_{3} \leq 120$ & $1,50 \leq E_{3} \leq 0,60$ \\
\hline 4 & Resíduos & $3 \leq \rho_{1} \leq 12$ & $3,10 \leq E_{1} \leq 3,90$ \\
\hline 5 & Material de cobertura do aterro com chorume & $38 \leq \rho_{5} \leq 106$ & $1,00 \leq E_{5} \leq 1,40$ \\
\hline 6 & Resíduos & $5 \leq \rho_{6} \leq 7$ & $2,90 \leq E_{6} \leq 10,00$ \\
\hline 7 & Sedimentos predominantemente arenosos (secos?) & $1760 \leq \rho_{7} \leq 3.253$ & - \\
\hline
\end{tabular}



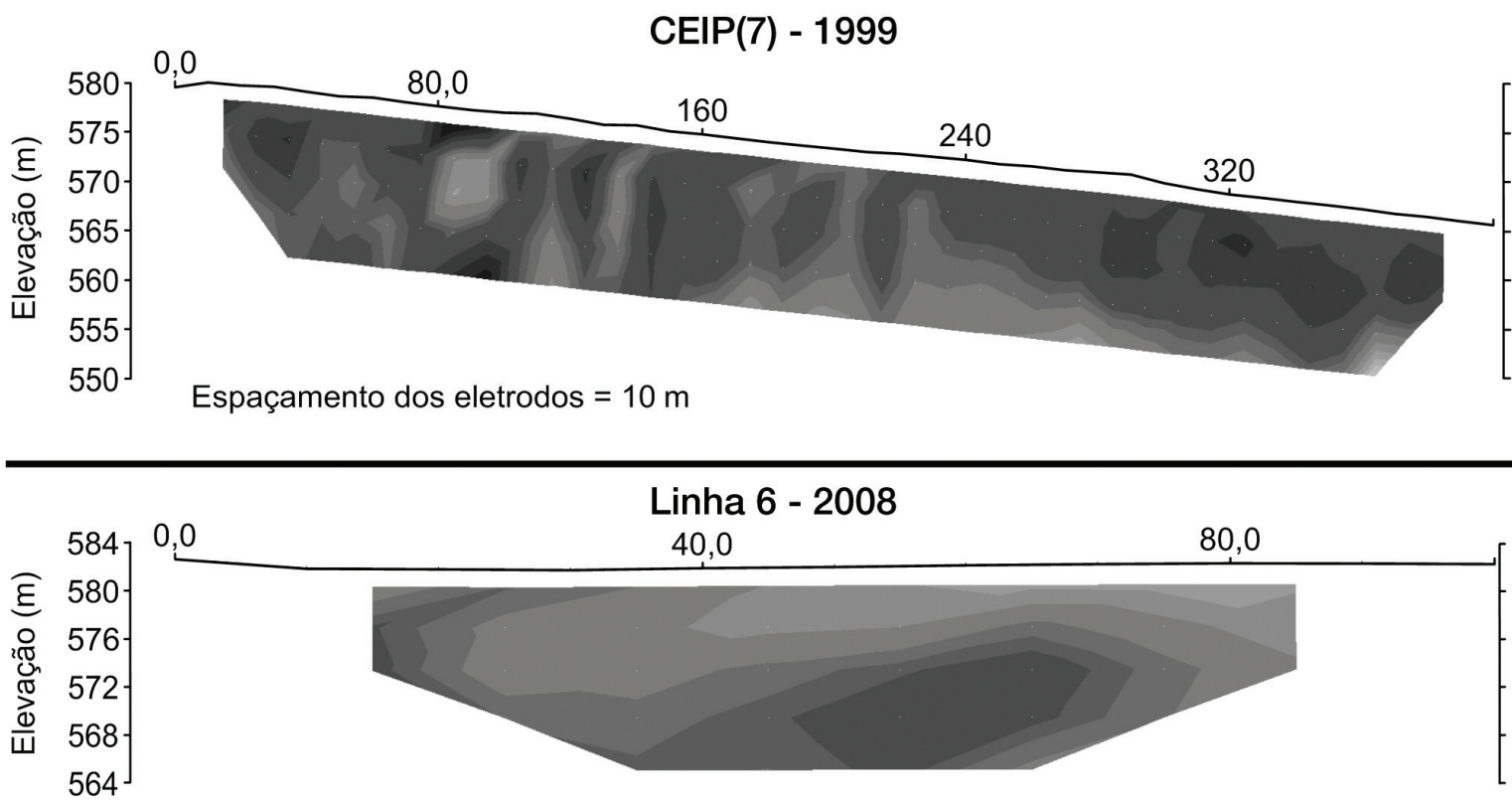

Espaçamento dos eletrodos $=10 \mathrm{~m}$

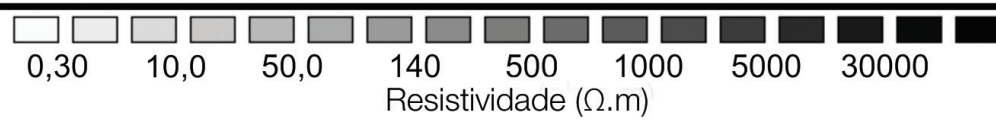

Figura 6. Seções de resistividade dos ensaios CEIP(7) e Linha 6 (Bortolin, 2009).
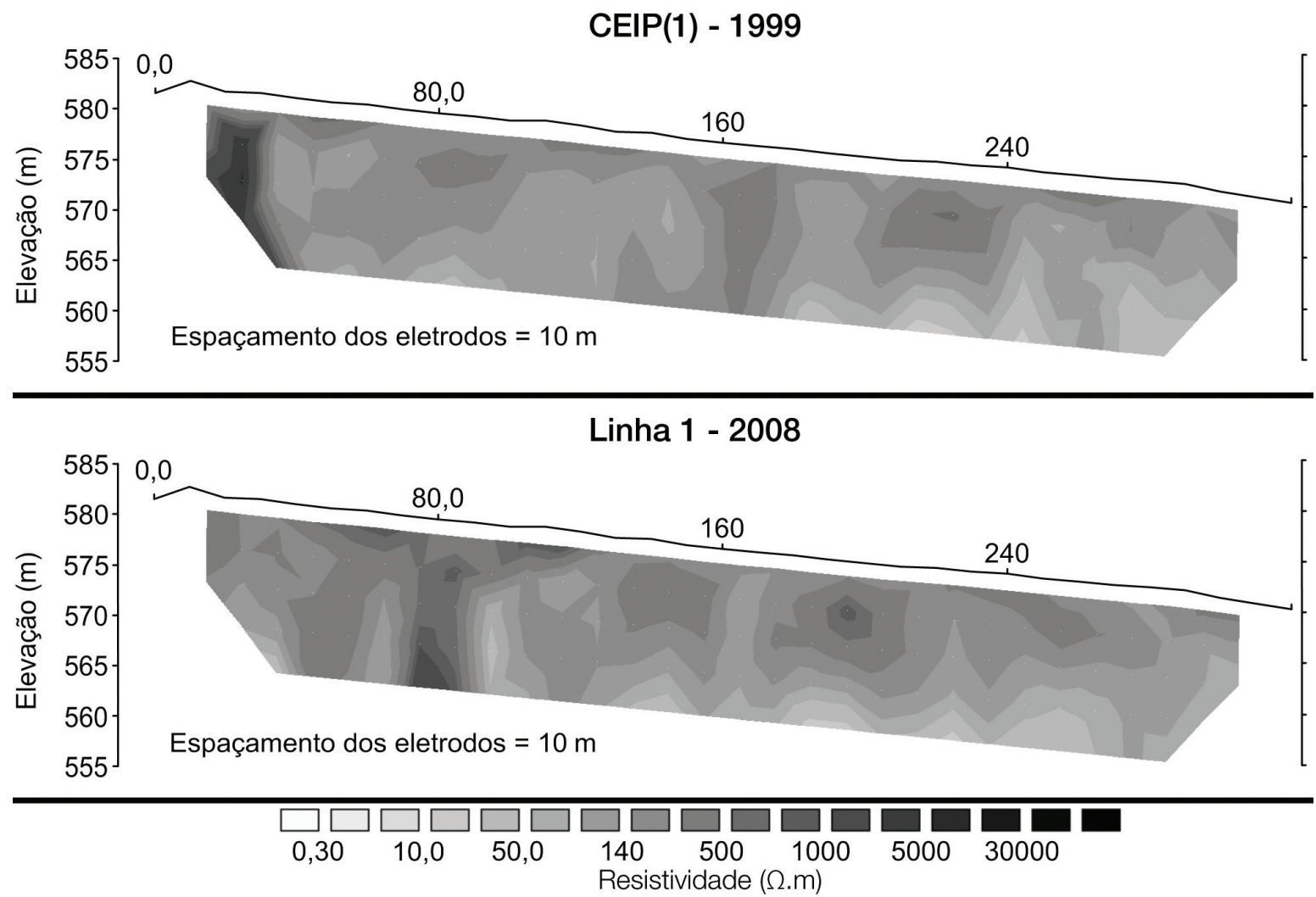

Figura 7. Seções de resistividade dos ensaios CEIP(1) e Linha 1 (Bortolin, 2009). 
subterrâneo local é para sudoeste (Tandel, 1998; Moura, 2002; Bortolin, 2009), assim como a orientação dessa linha.

No extremo esquerdo da seção da Linha 1 de 2008 (Figura 7) verifica-se um incremento nos valores de resistividade, atingindo valores típicos de sedimentos arenosos da Formação Rio Claro, o qual pode indicar uma tendência de recuperação natural da área antes contaminada.

\section{Monitoramento temporal: CEIP(2) e Linha 2}

$\mathrm{O}$ ensaio CEIP(2) foi executado quando o aterro encontrava-se em operação, sendo que a disposição dos resíduos era feita no sentido aproximado Norte-Sul e a frente dos resíduos ainda não havia atingido o limite Sul. Portanto, a região onde foi realizado o referido ensaio foi a última a receber os resíduos, justificando os elevados valores de resistividade encontrados.

A seção correspondente a este ensaio (Figura 8) apresenta-se majoritariamente resistiva, com valores maiores ou iguais a $140 \Omega$.m, isentando quase por completo a possibilidade de haver contaminação do subsolo nesse local. Pequenas zonas de baixa resistividade ( $\geq 50 \Omega$.m) em profundidades maiores que $6 \mathrm{~m}$, nesse contexto, podem indicar o nível freático (Moura, 2002).

A Linha 2 foi realizada no mesmo local do ensaio CEIP(2) e, apesar dos valores máximos e mínimos idênticos, a distribuição desses valores em cada seção é totalmente diferente.

Por meio da Linha 2 foi possível delimitar a cava de resíduos, entre as estacas de 35 e $40 \mathrm{~m}$ da seção. À esquerda desse ponto ocorrem resistividades acima de $140 \Omega$.m, refletindo os sedimentos predominantemente arenosos da Formação Rio Claro isentos de contaminação. À direita da estaca de $40 \mathrm{~m}$ têm-se uma grande zona de baixa resistividade $\left(\rho_{\mathrm{a}} \leq 50 \Omega . \mathrm{m}\right)$, relativamente ao restante da seção, associada à presença de resíduos e ao provável sentido de migração da pluma de contaminação: este é o fluxo principal, em direção ao Sul do aterro.

\section{Monitoramento temporal: CEIP(3) e Linha 3}

Ambos os ensaios foram realizado no topo da cava resíduos, no sentido do eixo maior do aterro (Figura 1). Entretanto, o ensaio CEIP(3) foi executado quando o aterro ainda se encontrava em operação. Assim, foi possível detectar dois cenários distintos na respectiva seção (Figura 9): (1) a lateral da cava de resíduos, que corresponde aos valores maiores ou iguais a $140 \Omega . \mathrm{m}$ entre as estacas 0 e $80 \mathrm{~m}$; (2) resíduos em subsuperfície e material de cobertura contaminados por chorume, apresentando resistividades menores ou iguais a $50 \Omega$.m, entre as estacas 80 e $380 \mathrm{~m}$ (Moura, 2002).

Para que a Linha 3 pudesse ser executada foi necessário deslocar seu ponto inicial cerca de $90 \mathrm{~m}$ em relação ao ensaio CEIP(3). Isto porque o ponto inicial do ensaio de $1999 \mathrm{se} \mathrm{deu}$ no local onde, em 2008, estava sediada a administração do serviço de coleta de resíduos municipais, então operada pela Secretaria de Obras da Prefeitura de Rio Claro (SP).

Desse modo, não foi possível detectar a lateral da cava de resíduos, como na seção do ensaio CEIP(3). Porém, o cenário verificado em 2008 é bastante semelhante ao de 1999, onde a seção (Figura 9) se encontra dominada por valores de resistividade menores ou iguais a $50 \Omega$.m, também interpretados como resíduos misturados ao material de cobertura, contaminados por chorume.

Uma sutil diferença pode ser observada entre as duas seções, em relação à distribuição das resistividades: a ocorrência de zonas de muito baixa resistividade $(\leq 10 \Omega . \mathrm{m})$ na seção da Linha 3 aparenta ser menor que na seção do ensaio CEIP(3), o que pode refletir uma tendência de recuperação natural do ambiente, ainda em fase inicial, tentando retomar os valores padrões sem contaminação (background).

\section{Monitoramento temporal: CEIP(4) e Linha 4}

Em ambas as seções dos ensaios CEIP(4) e Linha 4 (Figura 10) é possível distinguir um dos limites laterais da cava de resíduos, caracterizado por valores de resistividade aparente maiores ou iguais a $140 \Omega$.m, a partir do ponto inicial até as estacas $20 \mathrm{e}$ $30 \mathrm{~m}$, aproximadamente (Moura, 2002; Bortolin, 2009).

A diferença de valores entre as duas seções verificada nessa região pode refletir a utilização do aterro: em 1999, quando o aterro encontrava-se em fase final de operação, a produção de chorume era mais acentuada, ocasionando a diminuição da resistividade elétrica na lateral da cava pela infiltração do percolado. No ano de 2008, com o aterro desativado há pelo menos 7 anos, verificam-se valores significativamente maiores, os quais podem ser associados a uma queda da geração e consequente diminuição da infiltração do percolado na lateral da cava de resíduos, ocasionando a elevação dos valores de resistividade elétrica locais.

O restante das duas seções apresenta situações semelhantes, interpretado como resíduos e material de cobertura contaminados por chorume, caracterizados por resistividade menores ou iguais a $50 \Omega . \mathrm{m}$.

Assim como verificado entre as seções dos ensaios CEIP(3) e Linha 3, a ocorrência de zonas de muito baixa resistividade ( $\leq 10 \Omega$.m) na seção da Linha 4 também aparenta ser menor que na seção do ensaio $\operatorname{CEIP(4),~fato~tam-~}$ bém associado à recuperação natural do ambiente.

\section{Monitoramento temporal: CEIP(6) e Linha 5}

O ensaio CEIP(6) foi realizado em uma estrada não pavimentada, externa ao aterro controlado e vizinha a ele (Figura 1), e que encontra-se sobre um divisor de águas, com quedas nas direções SE e NO, aproximadamente.

A zona de baixa resistividade $\left(\rho_{\mathrm{a}} \leq 50 \Omega . \mathrm{m}\right)$ localizada a partir da estaca de $155 \mathrm{~m}$ da seção (Figura 11) foi 

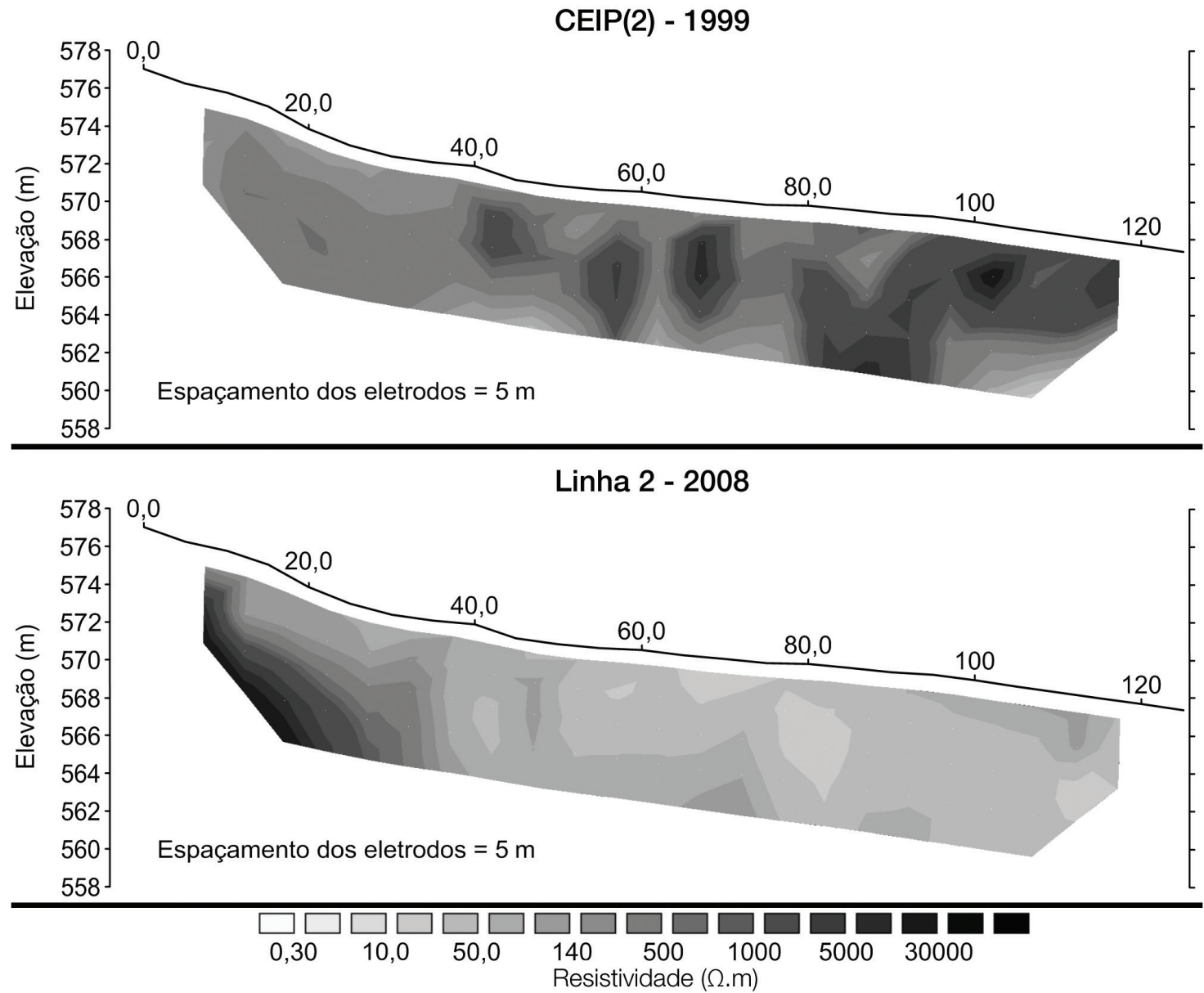

Figura 8. Seções de resistividade dos ensaios CEIP(2) e Linha 2 (Bortolin, 2009).
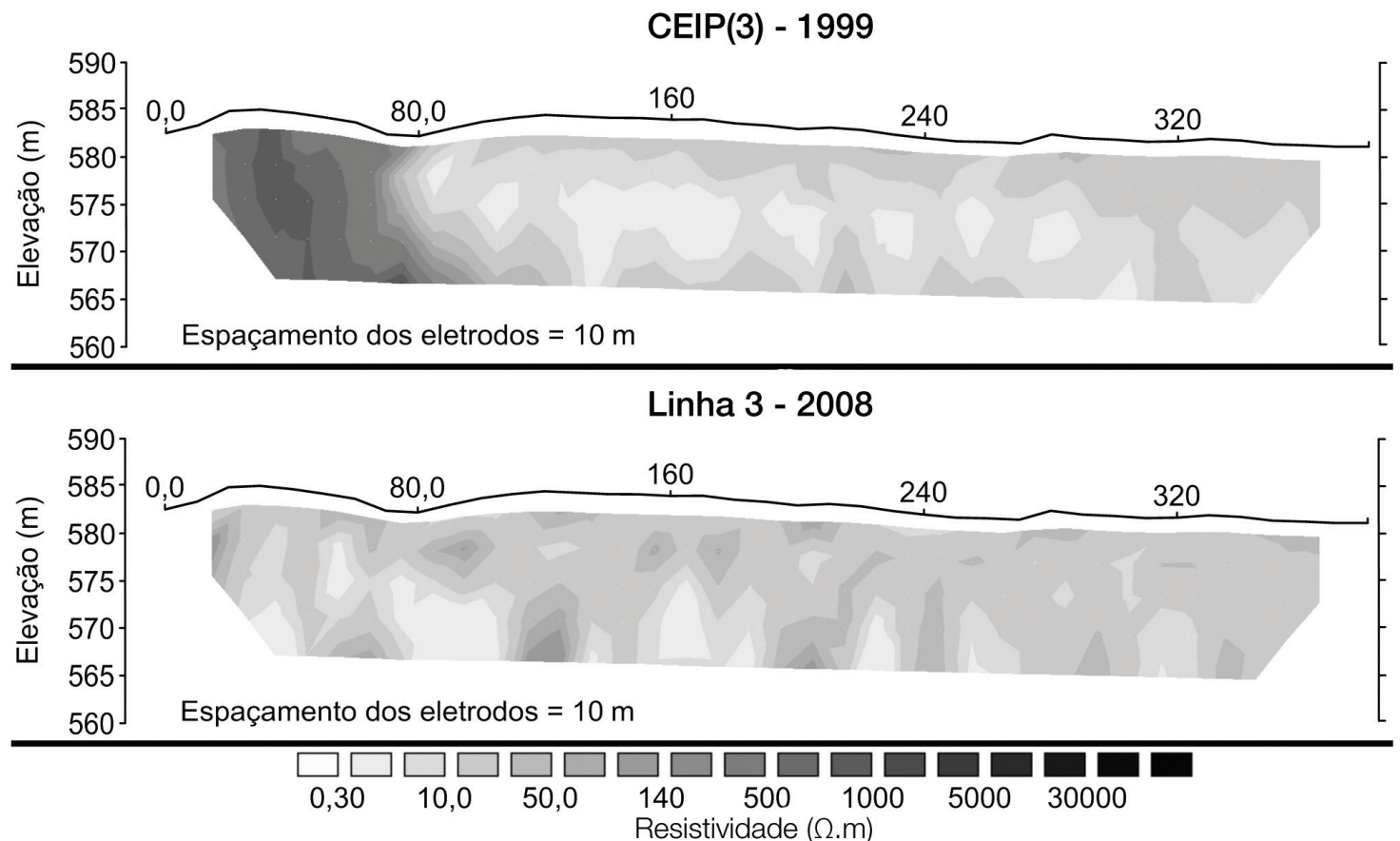

Figura 9. Seções de resistividade dos ensaios CEIP(3) e Linha 3 (Bortolin, 2009). 

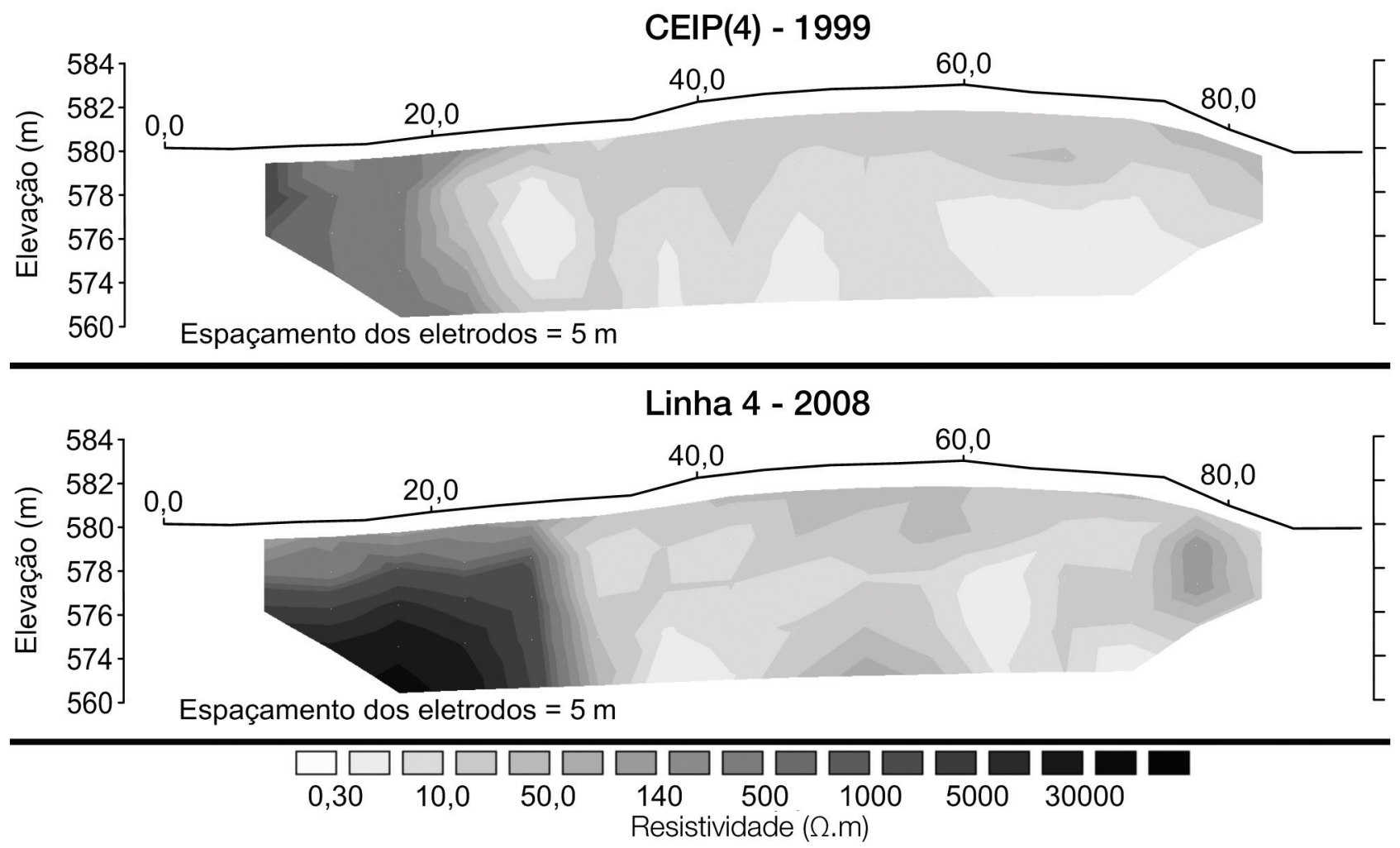

Figura 10. Seções de resistividade dos ensaios CEIP(4) e Linha 4 (Bortolin, 2009).

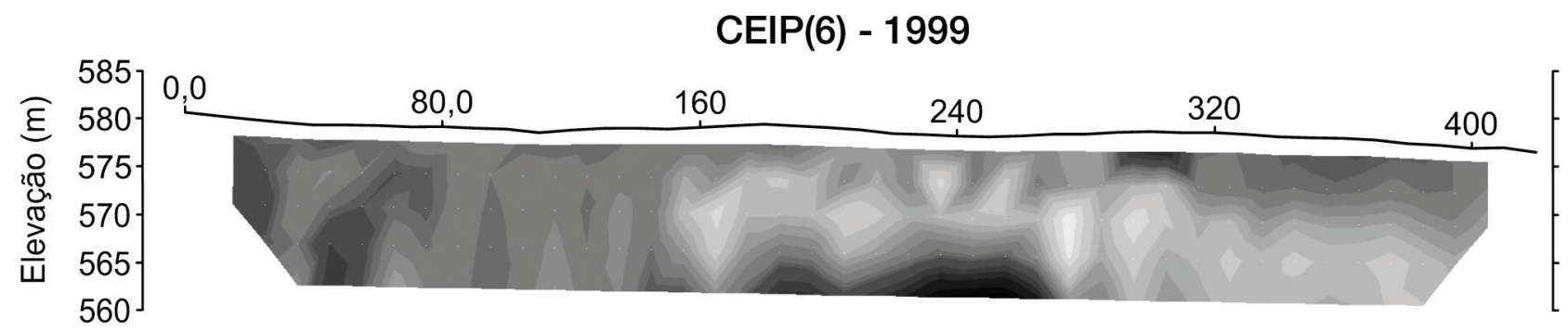

Espaçamento dos eletrodos $=10 \mathrm{~m}$

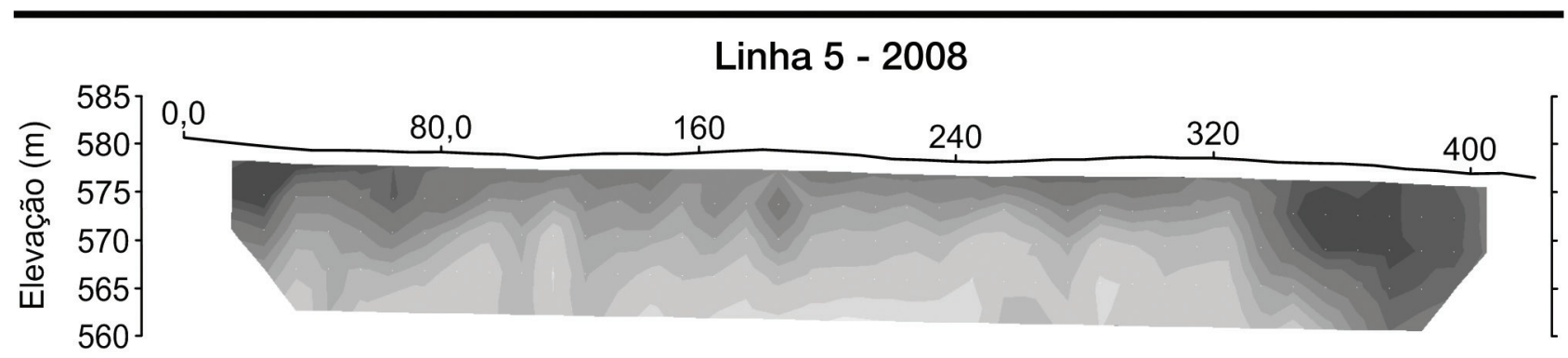

Espaçamento dos eletrodos $=10 \mathrm{~m}$

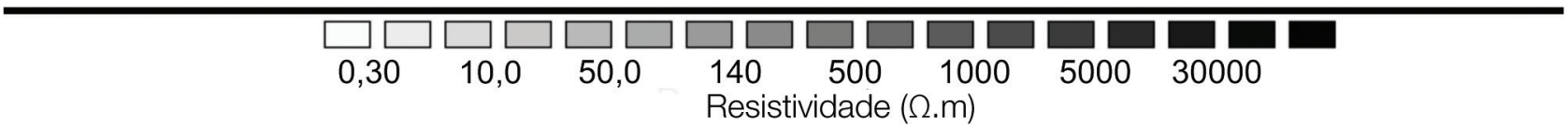

Figura 11. Seções de resistividade dos ensaios CEIP(6) e Linha 5 (Bortolin, 2009). 
atribuída ao fluxo de contaminantes proveniente da cava emergencial, onde os resíduos eram depositados no sentido aproximado Sul-Norte. Assim, no extremo direito da seção (estaca de $270 \mathrm{~m}$ ), a zona de baixa resistividade encontra-se em profundidades maiores comparativamente ao restante da seção, pois a produção e o fluxo de chorume são mais antigos nessa região. A região situada entre as estacas de 0 e $140 \mathrm{~m}$ apresenta valores de resistividade maiores ou iguais a $140 \Omega$.m, típicos de ambiente isento de contaminação, justificados pela inexistência de resíduos na cava emergencial nesse trecho durante a realização do ensaio.

A seção da Linha 5 exibe uma camada superficial, com aproximadamente $5 \mathrm{~m}$ de espessura e valores de resistividade maiores ou iguais a $140 \Omega$.m, interpretada como sedimentos predominantemente arenosos e material de empréstimo para cobertura dos resíduos. Tais valores também são encontrados nos flancos esquerdo e, principalmente, direito da seção, sendo esse último associado ao limite sul da cava emergencial.

A grande região com resistividades entre 0,3 e $50 \Omega . \mathrm{m}$, que se encontra a profundidades maiores que $5 \mathrm{~m}$ e se estende por quase toda a seção, pode ser associada à materiais geológicos contaminados por chorume proveniente do aterro controlado e da cava emergencial, pois, na ocasião da realização do ensaio, haviam resíduos depositados por toda a extensão de ambas as áreas.

Além disso, no topo do aterro controlado existem duas "lagoas" do sistema de recirculação de chorume e que ainda recebem volumes consideráveis de chorume, proveniente do novo aterro. É provável que parte do contaminante tenha migrado das "lagoas" em direção ao subsolo do local do ensaio, originando um fluxo no sentido Oeste (fluxo secundário), o que explicaria a zona de muito baixa resistividade $\left(\rho_{\mathrm{a}} \leq 10 \Omega . \mathrm{m}\right)$ encontrada na região central da seção e que coincide com a localização das duas "lagoas".

\section{Integração das seções de resistividade em mapas}

Com a finalidade de se obter uma visão integrada dos resultados das linhas de IE, elaborou-se o mapa de resistividade para cada nível de investigação, por meio de técnicas de interpolação dos dados. No mapa referente ao segundo nível de investigação (Figura 12), que corresponde à profundidade teórica de 5,10 m, é possível observar o sentido principal de migração do percolado para SE (seta contínua), acompanhando, aproximadamente, a declividade da topografia.

A essa profundidade também pode-se notar a existência de um fluxo secundário de contaminantes (seta tracejada), cujo sentido é em direção à estrada não pavimentada existente entre o aterro controlado e a cava de emergência. Este fluxo pôde ser constatado em campo, aflorando pela parede externa da cava de resíduos.

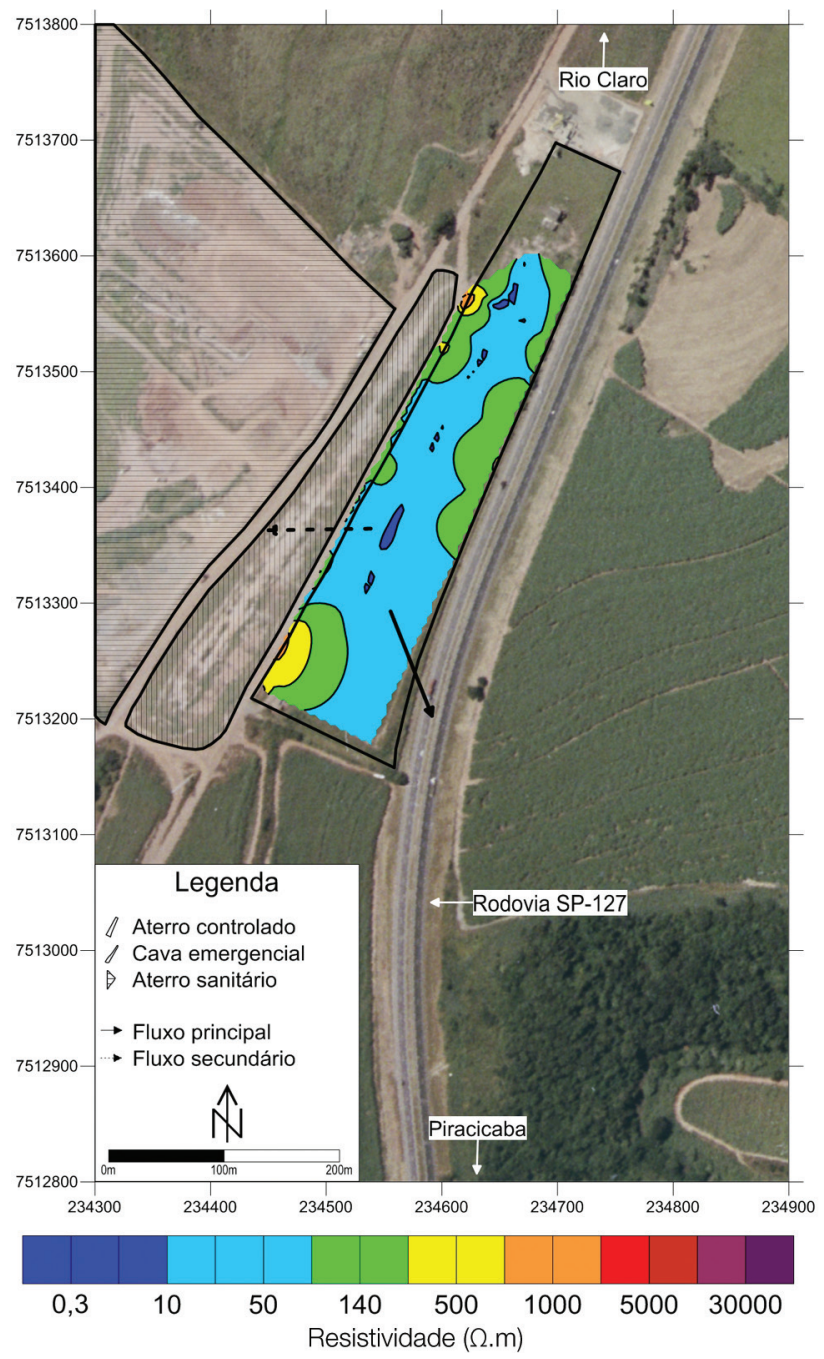

Figura 12. Mapa de resistividade do segundo nível de investigação das linhas de imageamento elétrico (profundidade teórica $=5,10 \mathrm{~m}$ ), exibindo os sentidos dos fluxos de contaminantes: principal para sudeste (seta contínua) e secundário para oeste (seta tracejada) (Bortolin, 2009).

Na porção central da imagem podem ser verificadas zonas de muito baixa resistividade $\left(\rho_{\mathrm{a}} \leq 10 \Omega . \mathrm{m}\right)$, indicando tratar-se de provável concentração de percolado ocasionada pela existência das "lagoas" de chorume no topo da cava de resíduos.

\section{CONCLUSÕES}

Os resultados indicaram alterações nos valores de resistividade e nas dimensões da pluma de contaminação. Relativamente ao ano de 1999, a pluma mostrou-se maior e mais profunda em 2008, contrariando o que se esperava para um aterro desativado há, pelo menos, 10 anos. As "lagoas" do antigo sistema de recirculação de chorume, mantidas quase que 
constantemente cheias, parecem ter contribuído significativamente para o aumento das dimensões da pluma.

Desse modo, pode-se afirmar que a metodologia empregada neste trabalho mostrou-se plenamente satisfatória para tal propósito e pode ser aplicada em semelhantes estudos dos mais diversos locais de disposição de resíduos, uma vez que são usuais contrastes de valores entre o meio natural não contaminado e a porção contaminada. Assim, os métodos geofísicos, em especial o método da eletrorresistividade, constituem comprovadamente uma alternativa confiável, expedita e menos onerosa que os métodos tradicionais de diagnóstico ambiental.

Por fim, cabe aqui uma ressalva: os resultados dos métodos geofísicos fornecem indícios da existência de substâncias contaminantes em solos e águas subterrâneas, e não são suficientes por si só para se afirmar a ocorrência de contaminação. Para isto e para se determinar o grau de contaminação de uma área, devem ser realizadas obrigatoriamente análises físico-químicas de amostras de solo e água, obtidas por meio de sondagens e poços de monitoramento.

\section{REFERÊNCIAS}

BORTOLIN, J. R. M. Monitoramento temporal da pluma de contaminação do aterro controlado de Rio Claro (SP) por meio do método da eletrorresistividade. 2009. Dissertação (Mestrado em Geociências e Meio Ambiente) - Universidade Estadual Paulista "Júlio de Mesquita Filho", Rio Claro.

BRAGA, A. C. O. Métodos geoelétricos aplicados na caracterização geológica e geotécnica - Formações Rio Claro e Corumbataí, no município de Rio Claro - SP. 1997. 169f. Tese (Doutorado em Geociências e Meio Ambiente) - Instituto de Geociências e Ciências Exatas, Universidade Estadual Paulista "Júlio de Mesquita Filho", Rio Claro.

BRASIL. CONSELHONACIONALDOMEIOAMBIENTE. Estabelece critérios e diretrizes para o licenciamento ambiental de aterro sanitário de pequeno porte de resíduos sólidos urbanos. Resolução n ${ }^{\circ} 404$, de 11 de novembro de 2008. Diário Oficial da União: Brasília, v. 220, p. 93, nov. 2008.

BRASIL. INSTITUTO BRASILEIRO DE GEOGRAFIA E ESTATÍSTICA (IBGE). Pesquisa nacional de saneamento básico - 2000. 2002. Disponível em: <http://www.ibge.gov. br/home/estatistica/populacao/condicaodevida/pnsb/pnsb. pdf >. Acesso em: 27 nov. 2008.

BRASIL. Lei $\mathrm{n}^{\circ} 12.305$, de 2 de agosto de 2010. Política Nacional de Resíduos Sólidos. Diário Oficial da União: Brasília, v. 147, p. 3-7, ago. 2010.

BRAZ, J. A.; SILVA, C. L. Avaliação do potencial energético do biogás de aterro sanitário gerado pelos resíduos sólidos domésticos do município de Rio Claro. In: CONGRESSO BRASILEIRO DE ENGENHARIA SANITÁRIA E AMBIENTAL, 21., 2001, João Pessoa. Anais... Florianópolis: 2001. Paginação irregular.

CAVALCANTI, S. S.; SATO, H. K.; LIMA, O. A. L. Geofísica elétrica na caracterização da hidrologia subterrânea na região do Aterro Metropolitano Centro, Salvador, Bahia. Revista Brasileira de Geofísica, v. 19, n. 2, p. 155-168, 2001.

COTTAS, L. R. Estudos geológico-geotécnicos aplicados ao planejamento urbano de Rio Claro-SP. 1983. Tese (Doutorado em Geologia), Universidade de São Paulo, São Paulo.

GEOTOMO SOFTWARE. RES2DINV ver. 3.4: 2D Resistivity and IP Inversion. Penang, Malaysia: Geotomo Software, 2002.

INTERPEX LIMITED. $I X 1 D$ v. 2.17. Golden, Co, USA: Interpex Limited, 2008.

LAGO, A. L.; ELIS, V. R.; GIACHETI, H. L. Aplicação integrada de métodos geofísicos em uma área de disposição de resíduos sólidos urbanos em Bauru-SP. Revista Brasileira de Geofisica, v. 24, n. 3, p. 357-374, 2006.

MOREIRA, C. A. Geofisica aplicada no monitoramento de área de disposição de resíduos sólidos domiciliares. 2009. Tese (Doutorado em Geociências e Meio Ambiente), Universidade Estadual Paulista "Júlio de Mesquita Filho", São Paulo.

MOREIRA, C. A.; AQUINO, W. F.; DOURADO, J. C. Aplicação do método eletromagnético indutivo (EM) no monitoramento de contaminantes em subsuperfície. Revista Brasileira de Geofisica, v. 25. n. 4. p. 413-420, 2007.

MOREIRA, C. A.; BRAGA, A. C. O. Aplicação de métodos geofísicos no monitoramento de área contaminada sob atenuação natural. Revista Engenharia Sanitária e Ambiental, v. 14. n. 2. p. 257-264, 2009.

MOREIRA, C. A.; DOURADO, J. C. Monitoramento da atenuação natural de pluma de contaminação pelo método de radar de penetração no solo (GPR). Revista Brasileira de Geofísica, v. 25. n. 4. p. 389-398, 2007.

MOURA, H. P. Emprego da eletrorresistividade e da polarização induzida na caracterização geoelétrica de áreas de disposição de resíduos sólidos urbanos. 2002. Tese (Doutorado em Geociências e Meio Ambiente) - Universidade Estadual Paulista "Júlio de Mesquita Filho", Rio Claro.

MOURA, H. P.; MALAGUTTI FILHO, W. Métodos da eletrorresistividade e da polarização induzida aplicados 
no estudo do aterro controlado de Piracicaba-SP. Revista Geociências, São Paulo, v. 26, n. 1, p. 35-43, 2007.

MOURA, H. P.; MALAGUTTI FILHO, W. Métodos de eletrorresistividade e de polarização induzida aplicados na área de disposição de resíduos urbanos: Aterro Controlado de Rio Claro-SP. Revista Geociências, São Paulo, v. 22, n. Especial, p. 129-139, 2003.

ORELlANA, E. Prospeccion Geolectrica en Corriente Continua. Madrid, España: Paraninfo, 1972. 523p.

SÃO PAULO (estado). COMPANHIA AMBIENTAL DO ESTADO DE SÃO PAULO (CETESB). Glossário. 2008. Disponível em: $<\mathrm{http}: / / w w w . c e t e s b . s p . g o v \cdot b r / i n s t i t u c i o n a l /$ institucional/70-glossario > . Acesso em: 8 dez. 2008.

SÃO PAULO (estado). Lei no 12.300 , de 16 de março de 2006. Institui a Política Estadual de Resíduos Sólidos e define princípios e diretrizes. Diário Oficial: Estado de São Paulo, São Paulo, v. 116, n. 51, p. 1-4, mar. 2006.
SHIRAIWA, S.; LISOVSKY, S. P.; ELIS, V. R.; PORSANI, J. L.; BORGES, W. R. Estudos geofísicos integrados no lixão de Cuiabá, MT, Brasil: resultados preliminares. Revista Brasileira de Geofísica, v. 20, n. 3, p. 181-186, 2002.

SILVA, J. E.; LOUREIRO, E. M. L.; ELIS, V. R.; HIODO, F. Y.; PORSANI, J. L. Aplicação de ensaios elétricos e eletromagnéticos em problema de poluição ambiental. Revista Brasileira de Geofísica, v. 20, n. 3, p. 193-198, 2002.

TANDEL, Y. R. Contribuição ao estudo da poluição provocada no aqüifero freático e no solo pelo aterro controlado da cidade de Rio Claro, SP. 1998. Tese (Doutorado em Geologia) - Universidade de São Paulo, São Paulo.

ZAINE, J. E.; Geologia da Formação Rio Claro na folha Rio Claro (SP). 1994. Dissertação (Mestrado em Geociências) Universidade Estadual Paulista "Júlio de Mesquita Filho", Rio Claro. 